\title{
CHEMICAL DEFENSE IN HARVESTMEN (ARACHNIDA, OPILIONES): DO BENZOQUINONE SECRETIONS DETER INVERTEBRATE AND VERTEBRATE PREDATORS?
}

\author{
GLAUCO MACHADO, ${ }^{1, *}$ PATRICIA C. CARRERA, ${ }^{1}$ \\ ARMANDO M. POMINI, ${ }^{2}$ and ANITA J. MARSAIOLI ${ }^{2}$ \\ ${ }^{1}$ Museu de História Natural, Instituto de Biologia, Universidade Estadual de Campinas, \\ C.P. 6109, 13083-970 Campinas, SP, Brazil. \\ ${ }^{2}$ Instituto de Química, Universidade Estadual de Campinas, C.P. 6154 , \\ 13083-970 Campinas, SP, Brazil.
}

(Received February 4, 2005; revised July 14, 2005; accepted July 16, 2005)

\begin{abstract}
Two alkylated 1,4-benzoquinones were identified from the defensive secretion produced by the neotropical harvestman Goniosoma longipes (Gonyleptidae). They were characterized as 2,3-dimethyl-1,4-benzoquinone and 2-ethyl-3-methyl-1,4-benzoquinone. We tested the effectiveness of these benzoquinone secretions against several predator types, including invertebrates and vertebrates. Different predators were exposed to the harvestmen's gland secretion or to distilled water in laboratory bioassays. Our results indicate that secretions containing the 1,4-benzoquinones released by $G$. longipes can be an effective defense against predation, and that the effectiveness of the secretion is dependent on the predator type. The scent gland secretion repelled seven ant species, two species of large wandering spiders, and one frog species, but was not an effective defense against an opossum. Our study also demonstrates that the scent gland secretion of $G$. longipes can work as a chemical shield preventing the approach of three large predatory ants for at least $10 \mathrm{~min}$. The chemical shield may protect the harvestman against successive attacks of the same ant worker and also allow the harvestman to flee before massive ant recruitment. Our data support the suggestion that chemical defenses may increase survival with some but not all potential predators. This variation in defense effectiveness may result from many interacting factors, including the attack strategy, size, learning ability, and physiology of the predators, as well as the chemical nature of the defensive compounds, type of emission, and amount of effluent released by the prey.
\end{abstract}

* To whom correspondence should be addressed. E-mail: glaucom@unicamp.br 
Key Words-Allomone, antipredator defense, chemical defense, chemical shield, Formicidae, Philander, predation, Proceratophrys, 1,4-benzoquinones.

\section{INTRODUCTION}

The species of the order Opiliones are characterized by the presence of a pair of exocrine glands located at the anterior margins of the cephalothorax near the base of the second pair of legs (Shultz, 1990). These glands produce a variety of volatile secretions that are released under the threat of predation (Eisner et al., 1978). To date, nearly 30 species have had their secretions chemically characterized, and a phylogenetic pattern may be observed. Species belonging to the suborder Eupnoi produce a variety of acyclic compounds, such as short-chain ketones and alcohols among the sclerosomatids and naphthoquinones among the phalangiids (references in Roach et al., 1980). In the suborder Laniatores, species of the superfamily Travunioidea produce mainly terpenoids, whereas among the Gonyleptoidea, the secretion is composed of phenols and alkylated 1,4-benzoquinones (references in Eisner et al., 1978; Acosta et al., 1993; Gnaspini and Cavalheiro, 1998). Quinones are widely distributed in the scent gland secretions of arthropods such as insects and millipedes (Blum, 1981), but the particular alkylated quinones produced by harvestmen seem to be of more restricted occurrence (Eisner et al., 1978).

Although much is known about the chemical nature of the compounds produced by harvestmen, knowledge about their biological role is still scarce. Several authors suggest that the scent gland secretions in harvestmen could be used for intraspecific communication, including trail marking, sexual recognition, mutual attraction, and alarm (see Holmberg, 1986; Machado et al., 2002). However, the main function attributed to the scent secretion is defense against predators (review in Holmberg, 1986). Laboratory observations have shown that ants are repelled by the secretion released by the cosmetid Vonones sayi (Eisner et al., 1971), the leiobunine Leiobunum formosum (Blum and Edgar, 1981), and the gonyleptid Acanthopachylus aculeatus (Eisner et al., 2004). Anecdotal observations indicate that some spiders may be also deterred by harvestman secretions (e.g., Cloudsley-Thompson, 1958; Juberthie, 1976), but others are not (e.g., Bristowe, 1949; Immel, 1954). Recently, Eisner et al. (2004) demonstrated that the scent gland secretion of the harvestman A. aculeatus was unable to deter the attack of a lycosid spider. The effectiveness of the scent gland secretion against vertebrates is also controversial because some species of frog seem to present a strong aversive response (e.g., Edgar, 1971), whereas some mammals feast on harvestmen (e.g., Pelegatti-Franco and Gnaspini, 1996). Despite these 
field and laboratory observations, the defensive role of the secretion against invertebrate and especially vertebrate predators remains to be experimentally tested through a rigorous protocol.

In this study, we chemically characterized the scent secretion of Goniosoma longipes (Roewer, 1913; Gonyleptidae) and conducted a series of bioassays to test the effectiveness of the 1,4-benzoquinone secretions produced by this neotropical harvestman against several predator types. This is a comprehensive study on the defensive role of the fluids released by harvestmen and the first to assess experimentally that the specific alkylated benzoquinone secretions released by harvestmen can deter vertebrates. Because after releasing the odoriferous secretion, residual effluents remain on the harvestmen's body (Eisner et al., 1971), we also tested if the secretion can also work as a "chemical shield".

\section{METHODS AND MATERIALS}

Studied Species. The harvestman G. longipes is conspicuous (Figure 1A, B) and widespread in forested areas of southeastern Brazil. This species was chosen as the source of secretion because it is abundant in our study site and because individuals produce a great amount of secretion when disturbed (see Machado et al., 2000). Moreover, the ecology and behavior of the species were previously studied (see Machado and Oliveira, 1998; Machado et al., 2000), aiding the selection of more realistic potential predators. The external morphology of the ozopore of G. longipes has been described (see Figures 19 and 20 in Hara and Gnaspini, 2003), and the mode of emission occurs as follows: (a) first, a large transparent droplet of enteric fluid composed exclusively of water is regurgitated, slips along the lateral area of the dorsal scute, runs by capillarity in tegumentary grooves, and accumulates in the posterior portion of the body (Figure 1A); (B) if the harvestman is persistently disturbed, a second fluid may be secreted by the odoriferous glands, adding to the previously colorless fluid a yellowish coloration and a characteristic sour smell (Figure 1B). Sometimes, the secretion may also be sprayed as a jet directly toward the aggressor without mixing with enteric fluid (Machado et al., 2000; Hara and Gnaspini, 2003).

All individuals of $\mathrm{G}$. longipes used in this study were collected inside caves at the Parque Florestal do Itapetinga $\left(23^{\circ} 15^{\prime} \mathrm{S}, 46^{\circ} 45^{\prime} \mathrm{W}, 900-\right.$ to $1300-\mathrm{m}$ altitude, $1600 \mathrm{~mm}$ rain/year), Atibaia, São Paulo state, southeastern Brazil (for details on the study site, see Machado and Oliveira, 1998 and Machado et al., 2000). In the laboratory, adult $G$. longipes were maintained in a communal terrarium $(60 \times 40 \mathrm{~cm}$ base, $35 \mathrm{~cm}$ high) containing cotton wetted with water to maintain the humidity and fed with dead insects twice a week. 

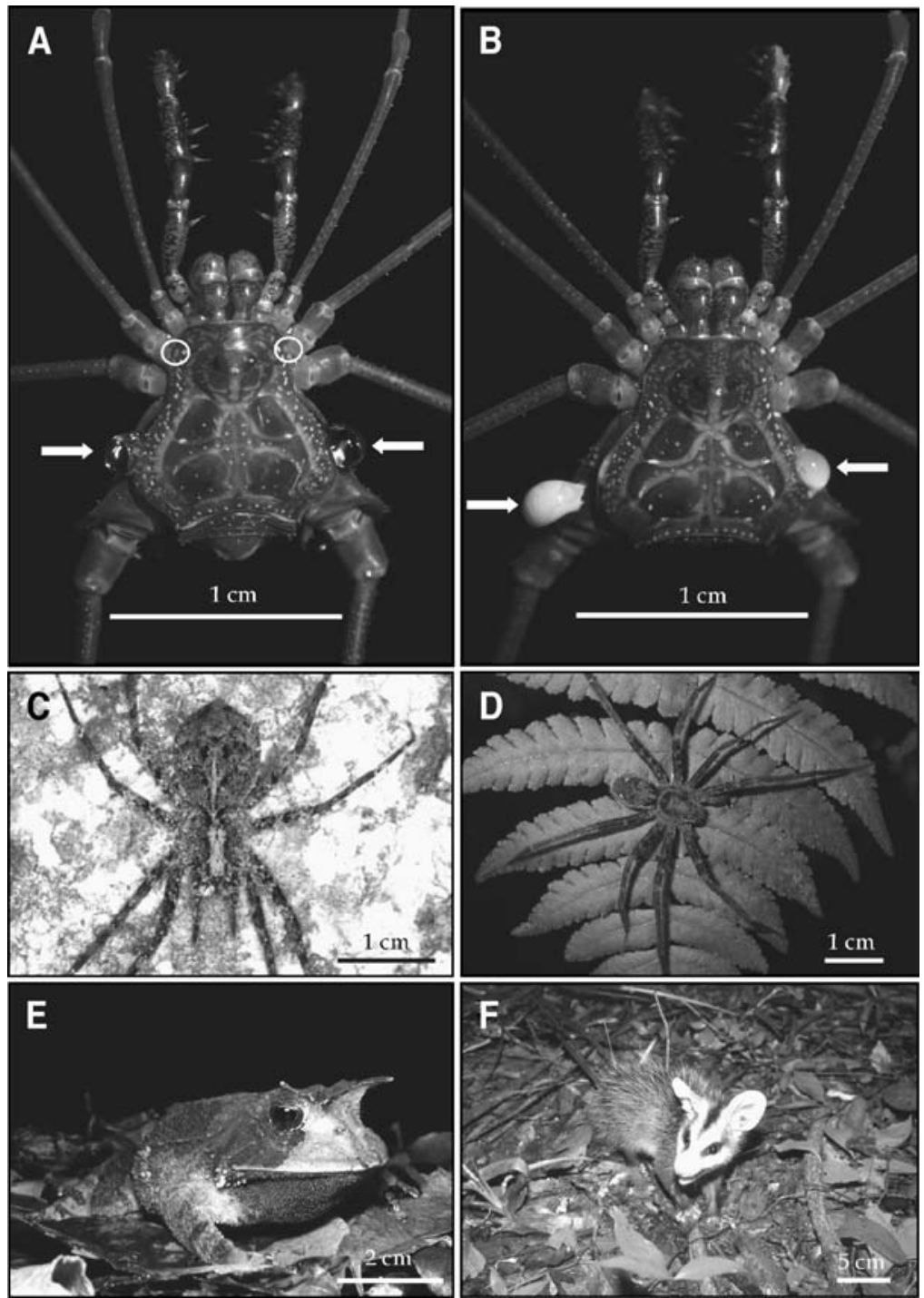

FIG. 1. Adult male of the harvestman G. longipes (A) with two droplets (arrows) of aqueous enteric fluid and (B) with a droplet of secretion (arrows) formed by the mixture of enteric fluid and defensive secretion (photos: B.A. Buzatto). The circles indicate the external opening of the scent gland. (C-F) Model predators used in the bioassays: $(C)$ the hunting spiders E. cyclothorax (photo: R.J. Sawaya) and (D) T. biocellata (photo: G. Machado); (E) the small horned frog Pr. boiei (photo: I. Sazima) and (F) the white-eared opossum D. albiventris (photo: E.G. Martins). 
Analyses of Defensive Secretions. Chemical secretions from G. longipes (about $8 \mathrm{mg} /$ individual) were collected by pressing cotton wools $(50-70 \mathrm{mg}$ ) onto the gland openings. The exudates were then either extracted with ethyl acetate (about $5 \mathrm{ml}$ ) and analyzed by gas chromatography-mass spectrometry (GC-MS) or with $\mathrm{CDCl}_{3} /$ tetramethylsilane (TMS) $(600 \mu \mathrm{l})$ for the NMR experiments. GC-MS analyses were carried out using an HP 6890/5973 system equipped with an HP5 fused silica capillary column $(30 \mathrm{~m} \times 0.25 \mathrm{~mm} \times$ $0.25 \mu \mathrm{m})$. Oven temperatures were programmed from 50 to $200^{\circ} \mathrm{C}$ at $10^{\circ} \mathrm{C}$ $\min ^{-1}$, and subsequently from 200 to $290^{\circ} \mathrm{C}$ at $16^{\circ} \mathrm{C} \min ^{-1}$. The injector temperature was $250^{\circ} \mathrm{C}$. Helium was used as carrier gas at a flow rate of $1 \mathrm{ml}$ $\min ^{-1}$. The electron impact mass spectrum (EIMS) were taken at $70 \mathrm{eV}$. Scanning speed was 3.54 scans s$^{-1}$ from $\mathrm{m} / \mathrm{z} 40$ to 450 . High-resolution mass spectrum was obtained from VG AutoSpec EI $(70 \mathrm{eV})$ equipment. Nuclear magnetic resonance (NMR) spectral data were acquired from Varian Inova spectrometer, operating at $499.88 \mathrm{MHz}$ for ${ }^{1} \mathrm{H}-\mathrm{NMR}$ and $125.71 \mathrm{MHz}$ for ${ }^{13} \mathrm{C}$-NMR. $\mathrm{CDCl}_{3}$ was used as solvent and TMS as an internal reference $(\delta=$ $0.0 \mathrm{ppm}$ ). Chemical shifts $\delta$ were recorded in ppm and coupling constants $J$ in Hz. Thin-layer chromatography analyses were performed on Merck $\mathrm{F}_{254}$ Aluminum Sheets, and the spots were visualized by UV light $(254 \mathrm{~nm})$. All solvents were of high analytical grade, bidistilled before using. Cotton wools were successively extracted with ethyl acetate, and the solvent was evaporated under vacuum.

Bioassays. The experiments were conducted from October 2002 to May 2003 and were performed between 19:00 and 23:00 hr under dim light conditions. Immediately before each trial, an adult individual of $G$. longipes was milked of secretion by seizing it by hand. Males and nonovigerous females were milked because the total amount of secretion released by them is not different $(8.3 \pm 4.4 \mathrm{mg})$. The exudate was collected with capillary tubes and diluted into a syringe with $100 \mu \mathrm{l}$ of distilled water. The secretion was mixed with water because many harvestman species, including G. longipes, dilute their own gland secretion in aqueous enteric fluid (Eisner et al., 1971, 1978; Acosta et al., 1993; Gnaspini and Cavalheiro, 1998; Hara and Gnaspini, 2003; see also Figure 1A). Different syringes were used for each experimental group. A different unmilked individual was used in each trial because repeated milking of the same individual could reduce the concentration and quantities of the secretion (Eisner et al., 1971). Different model predators were exposed to the harvestmen's gland secretion (treatment) or to distilled water (control).

Most laniatorean harvestmen, including G. longipes, have spines covering the body and legs and present a variety of defensive behaviors that may be divided in evasive responses (fleeing and dropping from the substrate) and aggressive responses (Machado, 2002). The latter includes several mechanisms that threaten, harm, or deter aggressors, such as attacking with the 
pedipalps, biting with the chelicerae, pinching with the sharp projections of the femora and coxae IV, and releasing scent gland secretions (Machado, 2002; Hara and Gnaspini, 2003). To test the potential defensive role of the glandular secretion only, and prevent other possible defensive mechanisms, individuals of $G$. longipes were not offered to the predators. Rather, the common cricket Gryllus gryllus (nearly $1 \mathrm{~cm}$ of body length) was used as model of prey in the experiments with spiders, frogs, and marsupials (see details below).

Tests with Ants. Two bioassays were conducted with ants: one in the field to test the potential of the scent gland secretion as a repellent and another in the laboratory to test the effectiveness as a "chemical shield". The field experiment consisted of the presentation of filter paper baits imbibed with honey solution, placed on plastic dishes $(5-\mathrm{cm}$ diam). These baits were randomly distributed on the forest floor $5 \mathrm{~m}$ from each other. In the treatment group, when ants had come to feed at the margin of the bait, the glandular secretion of one individual of $G$. longipes diluted in $100 \mu$ l of water was discharged in the center of the filter paper with a syringe. A similar procedure was used in the control group, but only $100 \mu \mathrm{l}$ of water were discharged in the bait. In both experimental groups, the number of ants in contact with the bait was counted before and $5 \mathrm{sec}$ after presentation of either secretion or water. Five ant species attended the baits in the field and were used in this experiment: (1) Formicinae-Camponotus lespesi (four baits; two controls and two treatments); (2) Myrmicinae-Pheidole sp. (eight baits; four controls and four treatments); (3) Ponerinae-Gnamptogenys sp. (eight baits; four controls and four treatments), Odontomachus chelifer (six baits; three controls and three treatments), and Pachycondyla striata (six baits; three controls and three treatments). After square-root transformations of the data, a repeated-measures ANOVA was performed on the number of workers of the five ant species in contact with the baits before and after the treatment in both experimental groups (Pagano, 1994).

Three ant species were used in the laboratory experiments: Pachycondyla villosa (one colony), Odontomachus hastatus, and Camponotus crassus (three colonies each). Inside the tray of each colony, we presented a glass coverslip $(1 \times 5 \mathrm{~cm})$ divided in two sides randomly designated by the flip of a coin as treatment or control. The treatment consisted of a filter paper $\left(1 \mathrm{~cm}^{2}\right)$ wetted with $200 \mu \mathrm{l}$ of a saturated sugar solution mixed with the glandular secretion of one individual of $G$. longipes. The control side contained only a filter paper $\left(1 \mathrm{~cm}^{2}\right)$ wetted with $200 \mu \mathrm{l}$ of a saturated sugar solution. The ant's response was evaluated by counting the total number of workers feeding at the baits at 1-min intervals during $10 \mathrm{~min}$ after the first contact.

Tests with Spiders. Enoploctenus cyclothorax (Ctenidae) is a large (3to 5 -cm body length) wandering spider that is commonly found near cave 
entrances (Figure 1C) and occasionally preys on adult G. longipes (Machado et al., 2000; Machado, personal observations), as well as other gonyleptid harvestmen (Willemart and Kaneto, 2004). Trechalea biocellata (Trechaleidae) is also a large (2- to 3-cm body length) wandering spider, abundant in the study site (Figure 1D), which is generally found near river margins or in other moist habitats, such as caves. An adult male of this spider was once observed preying on a harvestman, probably a Discocyrtus (Gonyleptidae), at night (Machado, personal observations). Individuals of both spiders were collected at the Parque Florestal do Itapetinga, from October 2002 to May 2003. They were maintained in individual cages $(20 \times 10 \mathrm{~cm}$ base, $15 \mathrm{~cm}$ high) containing cotton wetted with water to maintain the humidity and starved for 5-6 d before the experiments. Only subadults and adults of both sexes of $T$. biocellata $(N=$ $40)$ and E. cyclothorax $(N=20)$ were used in the experiments. Individuals were offered a cricket, which they promptly took as prey. To ensure that the crickets were unable to promote injuries on the spiders, their hind legs (armed with several spines) were removed just before the experiment. After the spiders had started feeding, each individual was stimulated with either secretion of one harvestman diluted in $100 \mu \mathrm{l}$ of water (treatment) or the same volume of distilled water (control), applied with a syringe directly to the base of the chelicerae. Individuals that extricated the chelicerae and abandoned the prey within 5 min were scored as respondents (cf. Eisner et al., 1997). The number of spiders that released the prey was compared between the two experimental groups using a Fisher exact test (Pagano, 1994). The time between the presentation of secretion and the response of the spiders was compared between species using a Mann-Whitney $U$-test.

Tests with Frogs. The effectiveness of the scent secretion against frogs was tested using adults (16 males and 4 females) of the small horned frog, Proceratophrys boiei (Leptodactylidae). The species is a leaf-litter dweller whose adults may reach $5-7.5 \mathrm{~cm}$ of body length (Figure 1E). Because of its large mouth, the diet of this species includes large ground arthropods, such as spiders, cockroaches, beetles, and crickets (Giaretta et al., 1998; Teixeira and Coutinho, 2002). Although there is no record of harvestmen among the food items of $P r$. boiei, other species of the genus, such as Pr. apendiculata, include harvestmen in their diet (Machado, personal observations). Small horned frogs $(N=20)$ were collected at the Parque Florestal do Itapetinga during the breeding season from November 2002 to January 2003. They were maintained in a communal terrarium $(60 \times 40 \mathrm{~cm}$ base, $35 \mathrm{~cm}$ high $)$ and starved $3 \mathrm{~d}$ before the experiments. They were offered a cricket, which they promptly took as prey. As soon as a frog swallowed the cricket, we caught it by hand, forced its mouth open, and used a syringe to inject either secretion of one harvestman diluted in $100 \mu \mathrm{l}$ of water (treatment) or the same volume of distilled water (control). Anurans generally catch their prey by a quick flip of 
their sticky tongue and may swallow chemically protected arthropods, such as millipedes or beetles, before the secretion of the prey is discharged (Eisner and Meinwald, 1966). Hence, the secretion might be released outside the mouth, inside the mouth, or even inside the stomach. Our experimental protocol simulated the mouth scenario. Individuals that regurgitated the prey within $5 \mathrm{~min}$ were scored as respondents. The number of frogs that regurgitated the prey was compared between the two experimental groups using a Fisher exact test (Pagano, 1994).

Tests with Opossums. The white-eared opossum Didelphis albiventris (Didelphidae) is a medium-sized mammal (0.5-2.0 kg; Figure 1F), whose omnivorous diet includes harvestmen (Cáceres and Monteiro-Filho, 2001; Cáceres, 2002). Although D. albiventris occurs at the Parque Florestal do Itapetinga, experimental individuals were collected at the Clube Náutico Araraquara $\left(21^{\circ} 43^{\prime} \mathrm{S}, 48^{\circ} 01^{\prime} \mathrm{W}, 653-\mathrm{m}\right.$ altitude, $1300 \mathrm{~mm}$ rain/year), a forested area near Américo Brasiliense, São Paulo state. In this locality, the species is abundant, and juvenile individuals (150-450 g) can be trapped using Sherman live traps. The opossums $(N=8)$ were maintained in individual cages for $12 \mathrm{hr}$ after collection, and $30 \mathrm{~min}$ before the experiment, they were transferred to a dark closed box $(60 \times 40 \mathrm{~cm}$ base, $35 \mathrm{~cm}$ high) and fed with a piece of banana to bring all of them to a similar hunger level.

The presentation of the prey was made by using a tube inserted in the box's wall that placed the cricket in the center of the cage. The first cricket introduced in the cage had a $4 \times 8 \mathrm{~mm}$ piece of filter paper carefully placed under its wings (no glue was used), wetted with the glandular secretion of one individual of G. longipes diluted in $100 \mu \mathrm{l}$ of water (treatment). Two minutes after the introduction of the first cricket, a second cricket with a piece of filter paper wetted with $100 \mu \mathrm{l}$ of distilled water (control) under its wings was placed in the cage. Prey were offered in this sequence because if the first cricket was rejected and not the second, it would be possible to identify a rejection response. This second cricket was also a control of the hunger level of the opossums. We recorded the time elapsed between the presentation of the crickets and the attack of the opossums, as well as the behavioral response of the animals to each type of prey. Because species of the genus Goniosoma are capable of ejecting their secretion forcibly as a spray (Machado, 2002; Hara and Gnaspini, 2003), one adult individual of $G$. longipes was also introduced in each cage after the presentation of the crickets to investigate the response of the opossums to this special type of emission.

Vouchers. One of the trials with frogs and all trials with the marsupials were video recorded, digitalized, and are available from the authors upon request. Voucher specimens of all studied species (except $D$. albiventris) were deposited at the Museu de História Natural da Universidade Estadual de Campinas and Museu de Zoologia da Universidade de São Paulo, Brazil. 
Chemistry. Two alkylated 1,4-benzoquinones were identified from the defensive secretion of the harvestman G. longipes (Figures 2 and 3):

2,3-Dimethyl-1,4-benzoquinone (compound 1). GC-MS m/z 136 (100), 108 (57), 107 (56), 82 (44), 79 (52), 65 (5), 54 (50); HRMS (EI, 70 eV): M $^{+}$ $136.05392\left(\mathrm{C}_{8} \mathrm{H}_{8} \mathrm{O}_{2}\right.$; calc. 136.05244); ${ }^{1} \mathrm{H}-\mathrm{NMR}\left(\mathrm{CDCl}_{3}\right.$, TMS, $\left.499.88 \mathrm{MHz}\right) \delta$ $(\mathrm{ppm})=2.04\left(\mathrm{~s}, \mathrm{H}-7\right.$ and H-8, 6H), $6.72\left(\mathrm{~s}, \mathrm{H}-5\right.$ and H-6, 2H); ${ }^{13} \mathrm{C}-\mathrm{NMR} \delta$ $(\mathrm{ppm})=187.39$ (C-1, C-4), 140.99 (C-2, C-3), 136.24 (C-5, C-6), 12.18 (C-7, C-8). Other spectroscopic methods as ${ }^{13} \mathrm{C}-\mathrm{NMR}$ DEPT-135 and DEPT-90, ${ }^{1} \mathrm{H}-{ }^{1} \mathrm{H}$ gCOSY, ${ }^{1} \mathrm{H}-{ }^{13} \mathrm{C}{ }^{1} J$ HSQC, and ${ }^{1} \mathrm{H}-{ }^{13} \mathrm{C}{ }^{n} J$ gHMBC were also employed (data not shown).

2-Ethyl-3-methyl-1,4-benzoquinone (compound 2). GC-MS m/z 150 (100), 135 (10), 122 (37), 121 (18), 107 (79), 82 (21), 79 (38), 67 (12), 54 (22); HRMS: $150.06824\left(\mathrm{C}_{9} \mathrm{H}_{10} \mathrm{O}_{2}\right.$; calc. 150.06810). For further spectroscopic data as ${ }^{1} \mathrm{H}-\mathrm{NMR}\left(\mathrm{CDCl}_{3}\right.$, TMS, $\left.499.88 \mathrm{MHz}\right),{ }^{13} \mathrm{C}-\mathrm{NMR}$, DEPT-135 and DEPT-90, ${ }^{1} \mathrm{H}-{ }^{1} \mathrm{H}$ gCOSY, ${ }^{1} \mathrm{H}-{ }^{13} \mathrm{C}{ }^{1} J$ HSQC, and ${ }^{1} \mathrm{H}-{ }^{13} \mathrm{C}{ }^{1} J$ gHMBC, see Table 1.

The fragmentation pattern of compound 1 under EIMS was compared with literature (Budzikiewicz et al., 1967), and it was identical to the spectrum reported for 2,3-dimethyl-1,4-benzoquinone. Because of molecular symmetry, compound 1 displayed two singlets in ${ }^{1} \mathrm{H}-\mathrm{NMR}$ spectrum: at $\delta=2.04 \mathrm{ppm}$ for six methyl protons and at $\delta=6.72 \mathrm{ppm}$ for the other two aromatic protons. This spectral simplicity allowed the structural identification of the other component in the mixture.

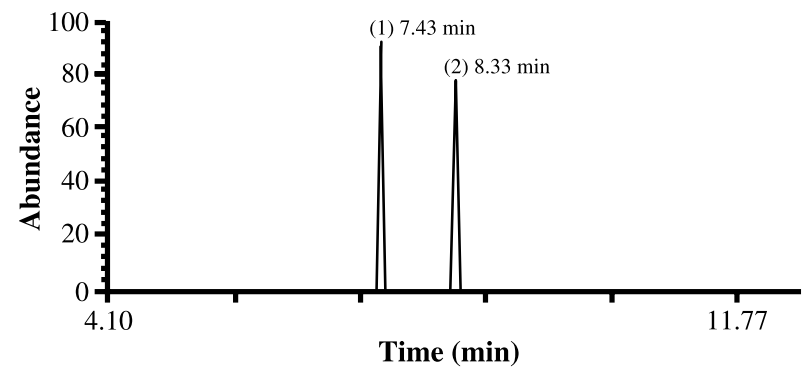

FIG. 2. GC-MS analysis of male G. longipes defensive secretion. Peaks corresponding to compounds 2,3-dimethyl-1,4-benzoquinone and 2-ethyl-3-methyl-1,4-benzoquinone are indicated as (1) and (2), respectively. 


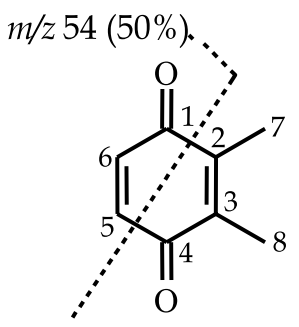

(1)

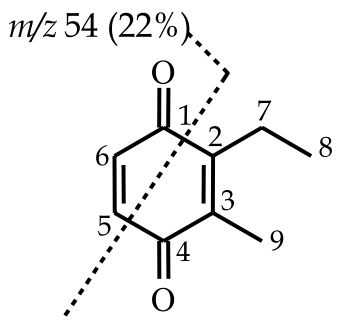

(2)

FIG. 3. Chemical defense compounds identified from the scent secretion of the harvestman $G$. longipes. The origin of the fragment $m / z 54$ in the EIMS spectra is also shown.

Compound 2 fragmentation pattern under EIMS did not match any mass spectral data available for other 1,4-benzoquinones derivatives identified in arthropods. The use of one and bidimensional NMR techniques allowed almost complete chemical shift assignments for this compound, which was identified as 2-ethyl-3-methyl-1,4-benzoquinone. The molecular formula $\mathrm{C}_{9} \mathrm{H}_{10} \mathrm{O}_{2}$ was confirmed by high-resolution mass spectrometry $\left(\mathrm{M}^{+}\right.$at $\mathrm{m} / \mathrm{z}$ 150.06824; calc.

TABle $1 .{ }^{1} \mathrm{H}$ And ${ }^{13} \mathrm{C}$ NMR $\left(\mathrm{CDCl}_{3}\right)$ Chemical ShIFT Assignments For 2-ETHYL-3-METHYL-1,4-BENZOQUINONE (COMPOUND 2)

\begin{tabular}{|c|c|c|c|c|c|c|}
\hline $\mathrm{C}$ & $\delta_{\mathrm{H}}$ & $\underset{{ }^{1} \mathrm{H}-{ }^{1} \mathrm{H}}{\operatorname{gCOSY}}$ & $\delta_{\mathrm{C}}$ & $\begin{array}{c}\text { HSQC, } \\
{ }^{1} \mathrm{H},{ }^{13} \mathrm{C}\left({ }^{1} J\right)\end{array}$ & $\begin{array}{c}\text { gHMBC, } \\
{ }^{1} \mathrm{H},{ }^{13} \mathrm{C}\left({ }^{\mathrm{n}} J\right)\end{array}$ & $\mathrm{DEPT}^{c}$ \\
\hline 1 & - & - & 187.10 & - & - & - \\
\hline 2 & - & - & 146.15 & - & - & - \\
\hline 3 & - & - & 140.37 & - & - & - \\
\hline 4 & - & - & 187.90 & - & - & - \\
\hline 5 & $6.71($ broad s, $1 \mathrm{H})$ & - & $136.19^{a}$ & $136.19(\mathrm{C}-5)^{b}$ & $187.90(\mathrm{C}-4)$ & $\mathrm{CH}$ \\
\hline 6 & $6.71($ broad s, $1 \mathrm{H})$ & - & $136.37^{a}$ & $136.37(\mathrm{C}-6)^{b}$ & $187.10(\mathrm{C}-1)$ & $\mathrm{CH}$ \\
\hline 7 & $2.51(\mathrm{q}, J 7.6 \mathrm{~Hz}, 2 \mathrm{H})$ & 1.06 & 19.73 & $19.73(\mathrm{C}-7)$ & $\begin{array}{r}12.84(\mathrm{C}-8) ; \\
140.37(\mathrm{C}-3) ; \\
146.15(\mathrm{C}-2) ; \\
187.10(\mathrm{C}-1)\end{array}$ & $\mathrm{CH}_{2}$ \\
\hline 8 & $1.06(\mathrm{t}, J 7.6 \mathrm{~Hz}, 3 \mathrm{H})$ & 2.51 & 12.84 & $12.84(\mathrm{C}-8)$ & $\begin{array}{r}19.73(\mathrm{C}-7) \\
146.15(\mathrm{C}-2)\end{array}$ & $\mathrm{CH}_{3}$ \\
\hline 9 & $2.05(\mathrm{~s}, 3 \mathrm{H})$ & - & 11.63 & $11.63(\mathrm{C}-9)$ & $\begin{array}{l}140.37(\mathrm{C}-3) \\
146.15(\mathrm{C}-2) ; \\
187.90(\mathrm{C}-4)\end{array}$ & $\mathrm{CH}_{3}$ \\
\hline
\end{tabular}

The letters $a$ and $b$ indicate interchangeable assignments, and $c$ indicates results from DEPT-90 and DEPT-135 experiments. Splitting pattern are as follows: $\mathrm{s}=$ singlet; $\mathrm{t}=$ triplet; $\mathrm{q}=$ quartet. 
150.06810). $\mathrm{A} \mathrm{CH}_{2} \mathrm{CH}_{3}$ substituent was easily characterized by the $\mathrm{A}_{3} \mathrm{X}_{2}$ spin system $(\delta=2.51 \mathrm{ppm}$ for $2 \mathrm{H}$ and $\delta=1.06 \mathrm{ppm}$ for $3 \mathrm{H})$ in the ${ }^{1} \mathrm{H}-\mathrm{NMR}$ spectrum, which was further confirmed by ${ }^{1} \mathrm{H},{ }^{1} \mathrm{H}$ homonuclear correlations spectrum (gCOSY). The substitution pattern of compound 2 was first suggested by the presence of the intense fragment at $\mathrm{m} / \mathrm{z} 54$ in the low-resolution mass spectrum, confirmed by HRMS (observed $\mathrm{m} / \mathrm{z}$ 54.01036; calc. for $\mathrm{C}_{3} \mathrm{H}_{2} \mathrm{O} \mathrm{m} / \mathrm{z}$ 54.01056; Figure 3). This was corroborated by the H-7/C-3, H-7/C-1, H9/C-2, and $\mathrm{H}-9 / \mathrm{C}-4{ }^{3} \mathrm{~J}$ correlations observed by ${ }^{1} \mathrm{H},{ }^{13} \mathrm{C}$ heteronuclear long-range correlations spectrum (gHMBC). Further spectroscopic methods as gHSQC $\left({ }^{1} \mathrm{H},{ }^{13} \mathrm{C}{ }^{1} J\right)$, DEPT-135, and DEPT-90 were also employed in chemical shift assignments for compound 2 (Table 1).

The chemical composition of defensive secretions from male and female individuals was the same in G. longipes, but the proportion of the two components is slightly different. Compound 2 always displayed smaller relative abundance in GC-MS analyses. This feature was also explored in the interpretation of the NMR experiments, in which compound 2 signals were always less intense than those from compound 1 .

Tests with Ants. The presentation of scent gland secretion in the treatment group induced a marked reduction in the number of ants tending the sugar baits in the field (Figure 4). This reduction was not observed in the control baits (Figure 4). The repellent effect was observed for recruiting species such as

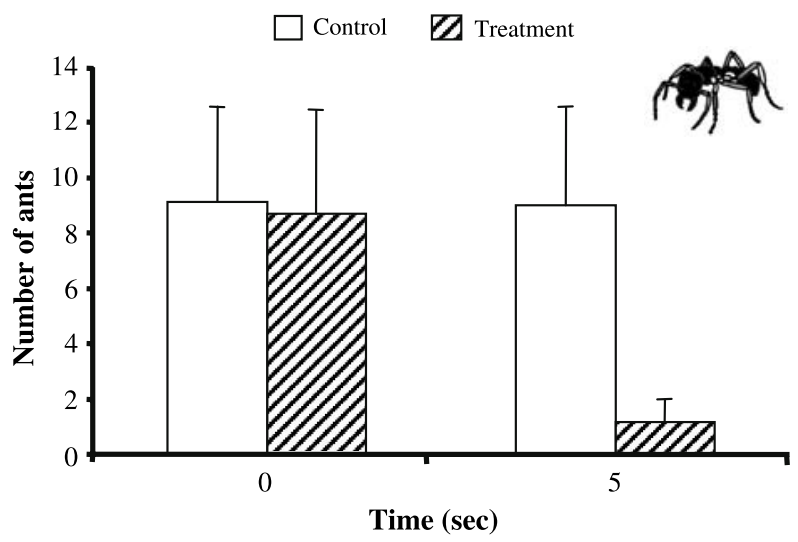

FIG. 4. Number of ants in the field tending sugar baits before (time $=0 \mathrm{sec}$ ) and after (time $=5 \mathrm{sec}$ ) stimulation with harvestman secretion (treatment) or distilled water (control). Data combined from 32 trials (16 controls and 16 treatments) on five species of ants. There was a significant effect of time (repeated-measures ANOVA, $F=13.77, P<$ 0.001 ) and experimental group (repeated-measures ANOVA, $F=39.61, P<0.001$ ). 
Pheidole sp., C. lespesi, and Gnamptogenys sp. and also for solitary hunters such as $O$. chelifer and $P$. villosa. After leaving the treatment baits (but not the control baits), workers of all tested species typically cleaned their antennae and front legs.
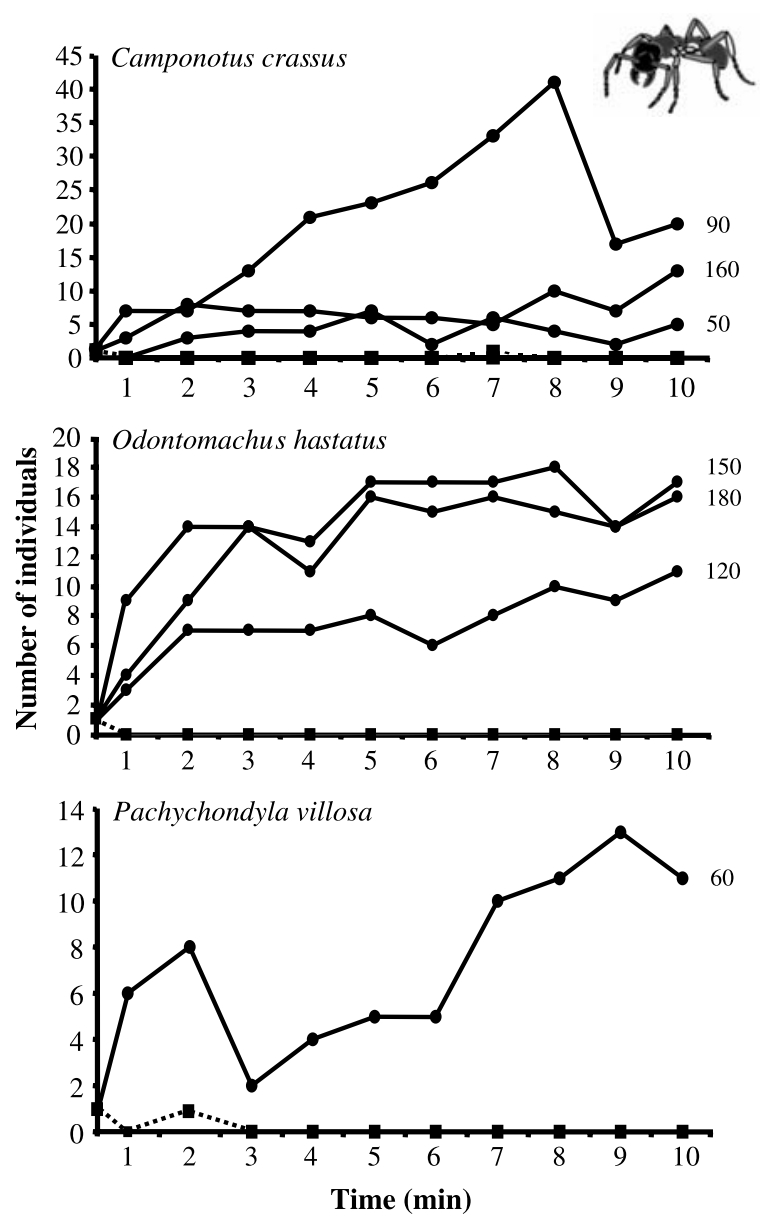

FIG. 5. Number of visits over time of three ant species tending control baits of sugar solution (circular dots, full line) and treatment baits of sugar solution mixed with harvestman secretion (square dots, dotted line) in the laboratory. The numbers at the right lateral of the graphics indicate the size of the ant colonies (for $C$. crassus and Odontomachus, three colonies each, and for P. villosa, one colony). Because the number of ants in contact with treatment baits was generally zero, it is not possible to distinguish the three dotted lines. 
In the laboratory, the number of ants tending control baits generally increased during the 10-min period, whereas few or no ant contacted treatment baits (Figure 5). The workers that touched the filter papers of the treatment baits presented a behavioral response similar to that observed in the field experiment,

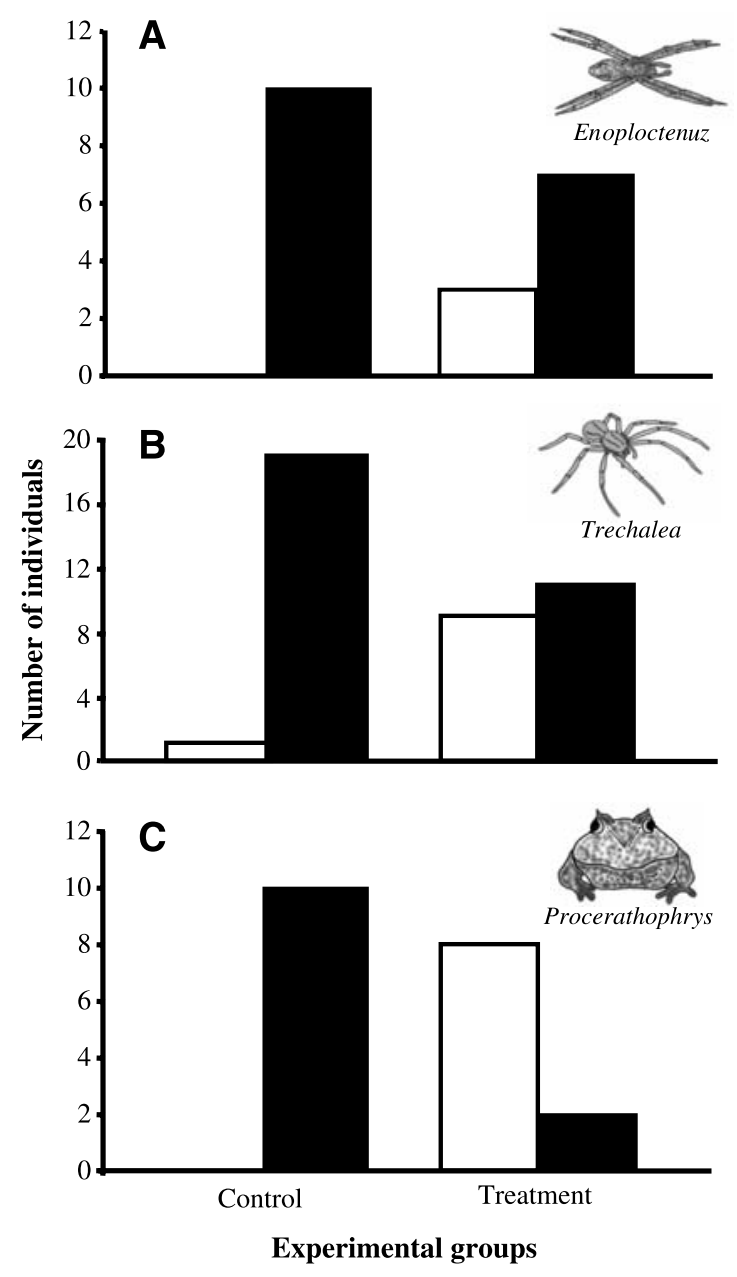

FIG. 6. Number of individuals of the spiders (A) E. cyclothorax and (B) T. biocellata that released (white bars) or not (black bars) the prey after stimulation with harvestman secretion (treatment) or distilled water (control). (C) Number of individuals of the small horned frog $P r$. boiei that regurgitated (white bars) or not (black bars) the prey after stimulation with harvestman secretion (treatment) or distilled water (control). 
i.e., they immediately cleaned their antennae and front legs and did not return to the bait.

Tests with Spiders. The frequency of individuals of E. cyclothorax (Fisher exact test, $P=0.003$ ) and $T$. biocellata (Fisher exact test, $P=0.008$ ) that released the prey in the treatment group was significantly higher than in the control group (Figure 6A, B). There was no difference between species in the frequency of individuals that released the prey in the treatment group (Fisher exact test, $P=0.43$ ). Respondent individuals of both species extricated their fangs, dropped the prey, and rubbed their mouthparts against the substrate. The time elapsed between the presentation of the secretion and the release of the prey also did not differ between species $(U=23.0 ; P=0.37)$ and ranged from 1 to $30 \mathrm{sec}$ in E. cyclothorax and from 1 to $50 \mathrm{sec}$ in T. biocellata.

Tests with Frogs. The frequency of individuals of Pr. boiei that regurgitated the prey in the treatment group was significantly higher than of those in the control group (Fisher exact test, $P=0.004$; Figure $6 \mathrm{C}$ ). Frogs in the treat-

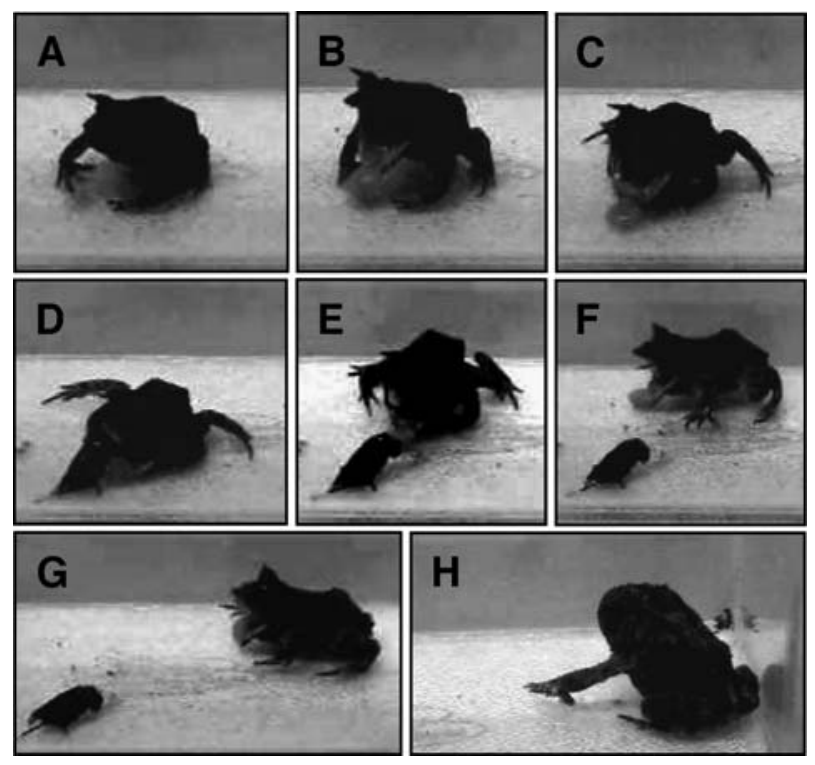

FIG. 7. (A-H) Sequence extracted from videotape showing the reaction of a small horned frog, Pr. boiei, to the scent gland secretion of the harvestman G. longipes. (A) The individual immediately before the test. (B) After the harvestman secretion was presented inside its mouth, the individual had abdominal contractions, and $(\mathrm{C}-\mathrm{E})$ regurgitated the cricket. $(\mathrm{F}-\mathrm{G})$ The frog scratched the mouth on the substrate and moved backward. $(\mathrm{H})$ Nearly $30 \mathrm{sec}$ after regurgitation, the individual still showed clear signs of aversion, maintaining the eyes shut and presenting strong abdominal contractions. 
ment group presented clear aversion reactions such as scratching the tongue on the substrate, shutting the eyes, and strong abdominal contractions (Figure 7). These behavioral reactions occurred both before and after prey regurgitation. Interestingly, for all respondent individuals, the prey was regurgitated alive.

Tests with Opossums. All individuals of D. albiventris consumed the crickets of both experimental groups. There was no clear sign of aversion when the opossums ingested the crickets wetted with secretion. All opossums also ingested adults of the harvestman $G$. longipes. Four of five subadult individuals subdued the harvestmen using the front legs to step on it, which probably promoted the releasing of secretion. After that, the harvestmen were grasped with the front legs and consumed. One subadult and three juveniles subdued the harvestmen using the snout to bite the prey. The biting elicited the release of a jet of secretion that probably reached the nose and the eyes of the opossums. In these cases, the opossums responded to the discharge by releasing the prey and wiping their eyes and snout with their front legs for nearly $2 \mathrm{~min}$. After this period, the opossums approached the dead body of the prey and ate it. In all cases, only the body of the harvestmen was consumed and the legs were discarded. During actual consumption, the opossum showed no clear signs of aversion, such as those presented by the small horned frogs.

\section{DISCUSSION}

Like most representatives of the superfamily Gonyleptoidea, the defensive secretion of the harvestman $G$. longipes is a mixture of compounds. The occurrence of alkylated 1,4-benzoquinones in G. longipes is chemotaxonomically in agreement with the constitution of the defensive secretions previously reported for other Gonyleptidae (Estable et al., 1955; Fieser and Ardao, 1956; Roach et al., 1980; Acosta et al., 1993; Eisner et al., 2004), including congeneric species, such as Goniosoma spelaeum (Gnaspini and Cavalheiro, 1998). The derivative 2,3-dimethyl-1,4-benzoquinone has been already identified in other harvestman species belonging to the families Cosmetidae, Gonyleptidae, and Manaosbiidae (Estable et al., 1955; Fieser and Ardao, 1956; Eisner et al., 1977, 2004; Roach et al., 1980; Acosta et al., 1993), but this is the first report of 2-ethyl-3-methyl-1,4-benzoquinone as a natural product. Moreover, the use of bidimensional nuclear magnetic resonance spectroscopy and high-resolution mass spectrometry is reported for the first time for chemical characterization of substances from harvestmen, providing additional protocols for studies of scent secretions in the group.

Alkylated benzoquinones are produced by harvestmen of the suborder Laniatores, millipedes of the orders Spirobolida, Spirostreptida, and Julida, and 
insects of the orders Coleoptera, Dermaptera, Blattodea, Isoptera, Orthoptera, and Hemiptera (Eisner and Meinwald, 1966; Blum, 1981). The caustic, irritating, and odoriferous properties of these substances may cause invertebrate predators to desist from the attack and to perform vigorous cleaning activities (Eisner and Meinwald, 1966). Recently, Eisner et al. (2004) showed that the secretion of the gonyleptid harvestman A. aculeatus (Pachylinae) was an effective deterrent against the ant Formica exsectoides. Using a different protocol, we here demonstrate that secretions containing the 1,4-benzoquinones produced by the gonyleptid G. longipes (Goniosomatinae) effectively repel five species of ants belonging to three subfamilies. This result is expected because 1,4-benzoquinones from the secretion of several arthropods, including cockroaches, carabid, and tenebrionid beetles, have been shown to be highly repellent to ants (Eisner, 1958a,b; Peschke and Eisner, 1987).

As long as their defensive stores last, chemically defended arthropods can repel potential predators, but when exudates are depleted, they may quickly fall prey (Whitman et al., 1994). Many harvestmen, including representatives of the families Biantidae, Cosmetidae, Gonyleptidae, Manaosbiidae, Phalangodidae, and Sclerosomatidae, have mechanisms of emission that increase the evaporating surface of the defensive secretion (reviewed in Acosta et al., 1993; Hara and Gnaspini, 2003). These mechanisms are divided in two main types: (1) emission of secretion as fine spray that moistens the dorsum of the harvestman and (2) displacement of the secretion along the lateral area of the dorsal scutum. Both types of emission are supposed to create a "chemical shield" around the body of the harvestman protecting the animal after the emission of secretion (Acosta et al., 1993; Hara and Gnaspini, 2003). Our study demonstrates that secretions containing the 1,4-benzoquinones released by $G$. longipes in fact work as a "chemical shield" preventing the approach of three large predatory ants for at least $10 \mathrm{~min}$. The "chemical shield" may protect the harvestman against the successive attacks of the same ant worker and also allow it to flee before massive ant recruitment. Because the families that have mechanisms to increase the evaporating surface of the defensive secretion are not closely related, it is possible that the "chemical shields" have evolved independently many times in the order Opiliones, and it may be related to the constant exposure to swarming insects, mainly ants.

The efficiency of the defensive secretion of harvestmen seems to vary among different spider families and genera. The ctenid Ctenus fasciatus is an important predator of gonyleptids in the wild (Gnaspini, 1996; Machado et al., 2000), and, therefore, it seems that the 1,4-benzoquinone secretions released by their prey have no effect on this spider. In captivity, individuals of the wolf spider Lycosa ceratiola (Lycosidae) were minimally affected by the effluent of the harvestman A. aculeatus, showing little response when the effluent was applied to their mouthparts as they fed on mealworms (Eisner et al., 2004). 
Using a similar protocol, we demonstrate here that secretions produced by $G$. longipes, whose composition is almost the same of A. aculeatus, are able to repel two large species of wandering spiders, E. cyclothorax (Ctenidae) and T. biocellata (Trechaleidae).

Contrary to what would be expected, Eisner et al. (2004) reported that live individuals of $A$. aculeatus were consistently rejected by spiders immediately after contact, before they were even prompted to release the defensive secretion. Three previous studies have reported that individuals of E. cyclothorax attack gonyleptid harvestmen but immediately retreat, avoiding biting the prey (Sabino and Gnaspini, 1999; Machado et al., 2000; Willemart and Kaneto, 2004). Eisner et al. (2004) discuss that $A$. aculeatus may contain additional chemical factors on the tegument that are repellent to spiders. It is also possible that such a repellent property derives from some residual action of the secretion, which may function as a "long persisting chemical shield", and/or that harvestmen actually release small amounts of secretion, not able to be detected visually. Experimental specimens that are seized or pressed normally produce excessive amounts of fluids because of a highly stressful situation, but minimal amounts of fluids may be secreted in "slightly unpleasant" situations before an extremely shocking situation appears (Whitman, personal communication).

As far as we know, our study is the first to evaluate the defensive role of 1,4-benzoquinone secretions produced by a harvestman species against vertebrate predators. Given that the great majority of the neotropical Laniatores are nocturnal (Machado, personal observations), we focused on two groups of vertebrates that are active at night: frogs and marsupials. Both vertebrate predators used here occur syntopically with G. longipes and may include harvestmen in their diets, thus being appropriate model organisms for the bioassays. The defensive effluent of $G$. longipes stimulated a strong aversive reaction on the frogs, causing them to regurgitate the prey, which left the frogs' stomach still alive. Similar results were previously obtained in experiments using millipedes and beetles that have quinone-producing glands (see Eisner and Meinwald, 1966). As occurs with spiders, the effectiveness of the harvestmen secretion in anurans may vary among different species or genera. Especially in the genera Bufo (Bufonidae) and Rana (Ranidae), which are mainly constituted by large-bodied species, there are many records of predation on harvestmen (Bristowe, 1949; Smith and Bragg, 1949; Jenssen and Klimstra, 1966; Berry, 1970; Clarke, 1974; Acosta et al., 1995). Therefore, it is possible that the size of the frog influences the resistance to the secretion, so that smaller species are more likely to be affected than the larger ones. However, this suggestion remains to be tested.

Marsupials seem to be highly resistant to the chemical defenses of arthropods (Eisner, 1965, but see Whitman et al., 1994). Moreover, field data on the diet of some Brazilian didelphids has revealed that gonyleptid harvestmen 
are important food items for at least three species: Philander opossum, which enter caves to feed on resting individuals of G. spelaeum (Pelegatti-Franco and Gnaspini, 1996), D. albiventris, and Didelphis aurita, in which harvestmen are the most frequent prey (Cáceres and Monteiro-Filho, 2001; Cáceres, 2002). Indeed, the tested white eared-opossum $D$. albiventris consumed all crickets in both experimental groups, as well as the adult harvestmen offered in our experiment. However, individuals that bit the prey were clearly affected by the spray of secretion released by $G$. longipes. This spray reached the eyes and the snout of the opossums, making them immediately release the dead prey and spend nearly 2 min grooming their face. Similar results were obtained by Eisner (1965) who offered the walkingstick Anisomorpha (Phasmida) to the mouse opossum Micoureus demearare. Individuals of Anisomorpha also sprayed their defensive secretion on the face of the marsupial, and, despite the "obvious discomfort" caused, the opossum attacked and consumed all walkingsticks that were introduced into the cage.

Many gonyleptids show gregarious habits, and among the representatives of the subfamily Goniosomatinae, this behavior is especially common (Machado, 2002). Recently, it was demonstrated that the defensive secretion of Goniosoma aff. proximum elicits alarming behavior among aggregated individuals and that the reaction response to the signal is negatively correlated with the size of the group (Machado et al., 2002). The time elapsed between the presentation of the secretion and the dispersion of the individuals ranged from 2 to $52 \mathrm{sec}$. If after the first strike toward a harvestmen aggregation, a naive marsupial takes up to $120 \mathrm{sec}$ to recover from the exposition to the secretion, there is enough time for all aggregated individuals to disperse. Because the aggregated individuals are not close relatives, there is no apparent advantage to the attacked harvestman, which dies after the first strike of the marsupial. However, the emission of defensive secretion by one individual may retard the attack of the marsupial and enhance the escape capability of conspecifics in an aggregation of harvestmen (see Discussion in Machado, 2002). Gregariousness, therefore, may be a defensive mechanism especially important against mammal predators because harvestman secretions seem not to be so effective.

The results of our study indicate that the 1,4-benzoquinones released by G. longipes are an effective defense against predation, and that the effectiveness of the secretion depends on the predator type. The emission of scent gland secretions repelled seven species of ants, two species of wandering spiders, and one species of frog, but it was not an effective defense against an opossum. Our data support the suggestion that chemical defenses may increase survival with some but not all potential predators (e.g., Krall et al., 1999; Staples et al., 2002; Eisner et al., 2004). This variation in defense effectiveness may result from many interacting factors, including on one hand the attack strategy, size, learning ability, and physiology of the predators and, on the other hand the 
chemical nature of the defensive compounds, type of emission, and amount of effluent released by the prey (Whitman et al., 1994). In this way, harvestmen are good model organisms because they release a great variety of compounds and are attacked by numerous potential and a few actual predators.

Acknowledgments - We are grateful to our friends A.C. Pellegrino, B.A. Buzatto, E.G. Martins, F. Osses, G.B.T. Egito, G.S. Requena, J.M. Fanton, L.M. Rossetto, S. Koehler, and T.M. Del Corso for helping during this study, to B.A. Buzatto for the photos of the harvestman, to E.G. Martins, I. Sazima, and R.J. Sawaya for the photos of the predators, to the staff of the Clube Náutico Araraquara for logistical support, to A.J. Santos (spiders), R. Cogni (ants), and E.G. Martins (marsupials) for taxonomic identifications, and to B.A. Buzatto, G.S. Requena, I. Sazima, P. Gnaspini, D.W. Whitman, and an anonymous reviewer for comments on an early draft of the manuscript. This study was supported by fellowships from the Fundação de Amparo à Pesquisa do Estado de São Paulo (FAPESP, no. 02/00381-0 and no. 03/09357-7).

\section{REFERENCES}

Acosta, L. E., Poretti, T. I., and Mascarelli, P. E. 1993. The defensive secretions of Pachyloidellus goliath (Opiliones: Laniatores: Gonyleptidae). Bonn. Zool. Beitr. 44:19-31.

Acosta, L. E., Pereyra, F. E., and PizzI, R. A. 1995. Field observations on Pachyloidellus goliath (Opiliones, Gonyleptidae) in Pampa de Achala, province of Córdoba, Argentina. Bull. Br. Arachnol. Soc. 10:23-28.

BerRY, P. Y. 1970. The food of the giant toad Bufo asper. Zool. J. Linn. Soc. 49:61-68.

BLuM, M. S. 1981. Chemical Defenses of Arthropods. Academic Press, New York.

Blum, M. S. and EdGAR, A. L. 1981. 4-Methyl-3-heptanone-identification and role in opilionid exocrine secretions. Insect Biochem. 1:181-188.

BRIsTOWE, W. S. 1949. The distribution of harvestmen (Phalangida) in Great Britain and Ireland, with notes on their names, enemies and food. J. Anim. Ecol. 18:100-114.

Budzikiewicz, H., DJerassi, C., and Williams, D. H. 1967. Mass Spectrometry of Organic Compounds. Holden-Day Inc., San Francisco.

CÁCEREs, N. C. 2002. Food habits and seed dispersal by the white-eared opossum, Didelphis albiventris, in Southern Brazil. Stud. Neotrop. Fauna Environ. 37:97-104.

CÁceres, N. C. and Monteiro-Filho, E. L. A. 2001. Food habits, home range and activity of Didelphis aurita (Mammalia, Marsupialia) in a forest fragment of Southern Brazil. Stud. Neotrop. Fauna Environ. 36:85-92.

Clarke, R. D. 1974. Food habitats of toads, genus Bufo (Amphibia: Bufonidae). Am. Midl. Nat. 91:140-147.

Cloudsley-Thompson, J. L. 1958. Spiders, Scorpions, Centipedes and Mites. Pergamon Press, London.

Edgar, A. L. 1971. Studies on the biology and ecology of Michigan Phalangida (Opiliones). Misc. Pub. Mus. Zool., Univ. Mich. 144:1-64.

EISNER, T. 1958a. The protective role of the spray mechanism of the bombardier beetle, Brachynus ballistarius Lec. J. Insect Physiol. 2:215-220.

EISNER, T. 1958b. Spray mechanism of the cockroach Diploptera punctata. Science 128:148-149.

EISNER, T. 1965. Defensive spray of a phasmid insect. Science 148:966-968.

EISNER, T. and MEINWALD, J. 1966. Defensive secretions of arthropods. Science 153:1341-1350. 
Eisner, T., Kluge, A. F., Carrel, J. E., and Meinwald, J. 1971. Defense of phalangid: liquid repellent administered by leg dabbing. Science 173:650-652.

Eisner, T., Jones, T. H., Hicks, K., Silberglied, R. E., and Meinwald, J. 1977. Quinones and phenols in the defensive secretions of neotropical opilionids. J. Chem. Ecol. 3:321-329.

EISNER, T., Alsop, D., and MeINWALD, J. 1978. Secretions of opilionids, whip scorpions and pseudoscorpions, pp. 87-99, in S. Bettini (ed.). Handbook of Experimental Pharmacology (Arthropod Venoms), Vol. 48. Springer-Verlag, Berlin.

Eisner, T., Morgan, R. C., Attygalle, A. B., Smedley, S. R., Herath, K. B., and Meinwald, J. 1997. Defensive production of quinoline by a phasmid insect (Oreophoetes peruana). J. Exp. Biol. 200:2493-2500.

Eisner, T., Rossini, C., GonzÁlez, A., and EIsner, M. 2004. Chemical defense of an opilionid (Acanthopachylus aculeatus). J. Exp. Biol. 207:1313-1321.

Estable, C., Ardao, M. I., Brasil, N. P., and Fieser, L. F. 1955. Gonyleptidine. J. Am. Chem. Soc. 77:4942.

FIESER, L. F. and ARDAO, M. I. 1956. Investigation of the chemical nature of Gonyleptidine. J. Chem. Ecol. 78:774-781.

Giaretta, A. A., Araújo, M. S., Medeiros, H. F., and Facure, K. G. 1998. Food habits and ontogenetic shifts of the litter dwelling frog Proceratophrys boiei (Wied). Rev. Bras. Zool. 15:385-388.

GNASNIPI, P. 1996. Population ecology of Goniosoma spelaeum, a cavernicolous harvestman from Southeastern Brazil (Arachnida: Opiliones: Gonyleptidae). J. Zool. 239:417-435.

Gnaspini, P. and Cavalheiro, A. J. 1998. Chemical and behavioral defenses of a Neotropical cavernicolous harvestman: Goniosoma spelaeum (Opiliones: Laniatores: Gonyleptidae). J. Arachnol. 26:81-90.

HARA, M. R. and GNASPINI, P. 2003. Comparative study of the defensive behavior and morphology of the gland opening area among harvestmen (Arachnida, Opiliones, Gonyleptidae) under a phylogenetic perspective. Arthropod Struct. Develop. 32:257-275.

Holmberg, R. G. 1986. The scent glands of Opiliones: a review of their function. Proc. 5th Cong. Int. Arachnol. 1983:131-133.

IMMEL, V. 1954. Zur Biologie und Phisiologie von Nemastoma quadripunctatum (Opiliones: Dyspnoi). Zool. Jahrb. (Syst.) 83:129-184.

Jenssen, T. A. and Klimstra, W. D. 1966. Food habits of the green frog, Rana clamitans, in southern Illinois. Am. Midl. Nat. 76:169-182.

Juberthie, C. 1976. Chemical defense in soil opiliones. Rev. Ecol. Biol. Sol 13:155-160.

Krall, B. S., Bartelt, R. J., Lewis, C. J., and Whitman, D. W. 1999. Chemical defense in the stink bug Cosmopepla bimaculata. J. Chem. Ecol. 25:2477-2494.

MACHADO, G. 2002. Subsociality, gregariousness, and defensive behavior in neotropical Goniosoma harvestmen (Arachnida: Opiliones). Insectes Soc. 49:388-393.

Machado, G. and Oliveira, P. S. 1998. Reproductive biology of the Neotropical harvestman Goniosoma longipes (Arachnida: Opiliones: Gonyleptidae): mating and oviposition behaviour, brood mortality, and parental care. J. Zool. 246:359-367.

Machado, G., Raimundo, R. L. G., and Oliveira, P. S. 2000. Daily activity schedule, gregariousness, and defensive behaviour in the Neotropical harvestman Goniosoma longipes (Arachnida: Opiliones: Gonyleptidae). J. Nat. Hist. 34:587-596.

Machado, G., Bonato, V., and Oliveira, P. S. 2002. Alarm communication: a new function for the scent gland secretion in harvestmen (Arachnida: Opiliones). Naturwissenschaften 89: $357-360$.

Pagano, R. R. 1994. Understanding Statistics in the Behavioral Sciences. West Publishing Company, Minneapolis, USA. 
Pelegatti-Franco, F. P. and Gnaspini, P. 1996. Use of caves by Philander opossum (Mammalia: Didelphidae) in Southeastern Brazil. Pap. Avulsos Zool. 39:351-364.

PESCHKE, K. and EISNER, T. 1987. Defensive secretion of a beetle (Blaps mucronata): physical and chemical determinants of effectiveness. J. Comp. Physiol., A 161:377-388.

RoACH, B., EISNER, T., and MeINWALD, J. 1980. Defensive substances of opilionids. J. Chem. Ecol. 6:511-516.

SABINO, J. and GNASPINI, P. 1999. Harvestman (Opiliones: Gonyleptidae) takes prey from a spider (Araneae: Ctenidae). J. Arachnol. 27:675-678.

ShUltZ, J. W. 1990. Evolutionary morphology and phylogeny of Arachnida. Cladistics 6:1-38.

SMith, C. C. and BRAGG, A. N. 1949. Observations on the ecology and natural history of Anura, VII. Food and feeding habits of the common species of toads in Oklahoma. Ecology 30:333-349.

Staples, J. K., Krall, B. S., Bartelt, R. J., and Whitman, D. W. 2002. Chemical defense in the plant bug Lopidea robiniae. J. Chem. Ecol. 28:601-615.

TeiXeIRA, R. L. and Coutinho, E. S. 2002. Hábito alimentar de Proceratophrys boiei (Wied) (Amphibia, Anura, Leptodactylidae) em Santa Teresa, Espírito Santo, sudeste do Brasil. Bol. Mus. Biol. Mello Leitão 14:13-20.

Whitman, D. W., Blum, M. S., and Alsop, D. W. 1994. Allomones: chemicals for defense, pp. 289-351, in D. L. Evans and J. O. Schmidt (eds.). Insect Defenses: Adaptative Mechanisms and Strategies of Prey and Predators. State University of New York, Albany.

Willemart, R. H. and Kaneto, G. E. 2004. On the natural history of the Neotropical spider Enoploctenus cyclothorax (Araneae, Ctenidae). Bull. Br. Arachnol. Soc. 13:53-59. 